\title{
New Imaging Techniques for Cardiovascular Autonomic Neuropathy: A Window on the Heart
}

\author{
MARTIN J. STEVENS, M.D.
}

\begin{abstract}
Cardiovascular autonomic neuropathy (CAN) is a common complication of diabetes, which results in disabling clinical manifestations and may predispose to sudden cardiac death. Recently, direct scintigraphic assessment of cardiac sympathetic integrity has become possible with the introduction of radiolabeled analogues of norepinephrine, which are actively taken up by the sympathetic nerve terminals of the heart. This article reviews how these techniques have been utilized to improve understanding of CAN complicating diabetes. Quantitative scintigraphic assessment of cardiac sympathetic innervation heart is possible with either [ $\left.{ }^{123} I\right]-$ metaiodobenzylguanidine (MIBG) and single photon emission computed tomography (SPECT) or $\left[{ }^{11} \mathrm{C}\right]$-hydroxyephedrine (HED) and positron emission tomography (PET). Studies in diabetic patients have explored the sensitivity of these techniques to detect CAN, characterize the effects of glycemic control on the progression of CAN and evaluate the effects of CAN on myocardial electrophysiology, blood flow regulation and function. Deficits of left ventricular (LV) $\left[{ }^{123} \mathrm{I}\right]-\mathrm{MIBG}$ and $\left[{ }^{11} \mathrm{C}\right]-$ HED retention have been identified in diabetic subjects without abnormalities on cardiovascular reflex testing consistent with increased sensitivity to detect CAN. Poor glycemic control results in the progression of LV tracer deficits, which can be prevented or reversed by the institution of near-euglycemia. Deficits begin distally in the LV and may extend proximally. Paradoxically, however, absolute HED retention is increased in the proximal segments of the severe CAN subjects consistent with regional "hyperinnervation." These regions also exhibit abnormal blood flow regulation. Impaired myocardial MIBG uptake correlates with altered LV diastolic filling and myocardial electrophysiological deficits and is predictive of sudden death. Scintigraphic studies have provided unique insights into the effects of diabetes on cardiac sympathetic integrity and the pathophysiological consequences of LV sympathetic dysinnervation. Future studies using complementary neurotransmitter analogues will allow different aspects of regional dysfunction to be characterized with the aim of developing therapeutic strategies to prevent or reverse CAN.
\end{abstract}

\section{INTRODUCTION}

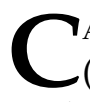
ARDiOVASCULAR AUTONOMIC NEUROPATHY (CAN) commonly complicates diabetes with widespread adverse clinical consequences, including refractory postural hypotension, ${ }^{1}$ pe- ripheral edema and neuropathy, ${ }^{2}$ and enhanced cardiac mortality. ${ }^{3-5}$ Indeed, CAN has been invoked in sudden cardiac death even in diabetic subjects without myocardial ischemia. ${ }^{3-7}$ Historically, the diagnosis of CAN has been performed utilizing cardiovascular reflex tests as-

Division of Endocrinology and Metabolism, Department of Internal Medicine, University of Michigan, and the Veterans Administration Ann Arbor Hospitals, Ann Arbor, Michigan. 
sessing heart rate variability (HRV). ${ }^{8}$ Abnormalities of cardiovascular reflex testing can be identified in 16-20\% of diabetic subjects, ${ }^{8-14}$ but symptoms of autonomic dysfunction are much rarer. ${ }^{15,16} \mathrm{CAN}$ may be broadly categorized into sympathetic and parasympathetic components, both of which are affected by diabetes. Cardiovascular reflex assessments are particularly sensitive at detecting abnormalities of parasympathetic function, ${ }^{14}$ but are less useful for the characterization of sympathetic deficits, which may only become evident when quite advanced. Additionally, the utility of reflex tests of autonomic integrity is limited by their inability to directly characterize autonomic dysfunction, which is necessary to determine the pathophysiological consequences of CAN. Since in diabetes complicated by CAN, the highest mortality rates appear to correspond to advanced deficits of cardiovascular sympathetic innervation, ${ }^{3}$ a technique for direct quantitation of cardiac sympathetic deficits is highly desirable.

Recently, scintigraphic techniques have emerged as important tools to directly assess cardiac autonomic integrity. Scintigraphic assessment of cardiovascular autonomic integrity is limited to the sympathetic component in part because of the relative sparsity of myocardial parasympathetic innervation. Direct assessment of cardiac sympathetic integrity in man has become possible with the introduction of radiolabeled analogues of norepinephrine (NE), which are actively taken up by the sympathetic nerve terminals of the heart. ${ }^{17-27}$ These tracers are taken up into the neuron by energydependent uptake-1,27,28 are nonmetabolized, and therefore identify the location of functioning sympathetic nerve terminals. Quantitative scintigraphic assessment of the pattern of sympathetic innervation of the human heart is possible with either $\left[{ }^{123} \mathrm{I}\right]$-metaiodobenzylguanidine (MIBG) or $\left[{ }^{11} \mathrm{C}\right]$-hydroxyephedrine (HED). These techniques may offer greater sensitivity to detect subtle degrees of CAN than is possible by reflex testing, and have emerged as useful tools to characterize the effects of diabetes on myocardial sympathetic innervation.

This article summarizes the results of studies using these tracers in patients with diabetes, which have thrown new light on this poorly understood chronic complication. These stud- ies have characterized the pattern of cardiac dysinnervation complicating diabetes, highlighted the importance of glycemic control in the development and/or progression of CAN, and have offered insights into the potential effect of CAN on myocardial electrophysiology, blood flow regulation, and function.

\section{METHODS}

Scintigraphic characterization of cardiac sympathetic integrity

MIBG. Radiolabeled analogues of NE have been designed to closely mimic the neuronal kinetics of NE. ${ }^{28} \mathrm{NE}$ undergoes highly efficient and dynamic recycling in the heart. NE is released exocytotically from neuronal vesicles into the interstitium, is retaken up into the neuronal cytoplasm by the uptake-1 transporter and then is either degraded by monoamine oxidase (MAO) or undergoes reuptake into neuronal vesicles. ${ }^{28}$ The first radiotracer developed for clinical studies of cardiac sympathetic integrity (and still the most widely utilized) is MIBG, ${ }^{29-31}$ a guanethidine derivative. This tracer is taken up into the postganglionic presynaptic sympathetic nerve terminals, stored in synaptic vesicles and is not metabolized by MAO. ${ }^{28}$ The specificity of MIBG for the sympathetic nerve terminals has been demonstrated in animal models, since myocardial MIBG retention, is dramatically reduced by disruption of sympathetic integrity by procedures such as the epicardial application of phenol, ${ }^{32-34}$ administration of 6-hydroxydopamine, ${ }^{30,32}$ or myocardial infarction. ${ }^{32,35}$ Decreased MIBG retention correlated with reduced myocardial NE content $^{30,32,33}$ and disruption of electrophysiological responses. ${ }^{34}$ In humans, myocardial MIBG retention is markedly reduced in the denervated, transplanted heart ${ }^{32,36}$ consistent with a neuronal localization. However, important quantitative differences in the kinetics of MIBG have emerged compared to $\mathrm{NE}^{30,37,38}$ suggesting that both nonspecific tissue uptake and washout may be increased. ${ }^{31}$ Despite the abundance of clinical studies utilizing this compound, the intraneuronal distribution of MIBG is relatively poorly characterized and may dif- 
fer across species. Reserpine (a blocker of vesicular NE uptake) for example, decreases the retention of MIBG in dog adrenal glands, suggesting a predominant intravesicular storage site. ${ }^{29}$ In rats, however, $50 \%$ of MIBG may reside in a nonneuronal compartment. ${ }^{39}$ The precise intraneuronal localization of MIBG in man is unclear.

The methodology for the quantitation of myocardial MIBG retention varies between different laboratories. [ $\left.{ }^{123} \mathrm{I}\right]-\mathrm{MIBG}$ is injected intravenously and single photon emission computed tomography (SPECT) commenced shortly postinjection using a gamma camera with a large field of view. Typically, imaging starts at a $45^{\circ}$ right anterior oblique position and proceeds counterclockwise at $6^{\circ}$ increments over $180^{\circ}$ circular orbit $(60 \mathrm{sec} / \mathrm{step})$. The SPECT study is repeated $2-4 \mathrm{~h}$ after tracer injection, prefiltered and then transaxial tomographic images reconstructed by filtered back projection. Horizontal and vertical long axis sections and short axis slices are generated. ${ }^{19}$ Short axis views are used for evaluation of $\left[{ }^{123} \mathrm{I}\right]-\mathrm{MIBG}$ uptake and washout. Early and late images are visually analyzed to evaluate homogeneity of myocardial [ $\left.{ }^{123} \mathrm{I}\right]-\mathrm{MIBG}$ distribution. Representative cuts are taken at basal, mid-ventricular and apical levels and each divided into segments. Global myocardial [ [ $\left.{ }^{123} \mathrm{I}\right]-$ MIBG uptake can be quantified in counts $\cdot \min ^{-1} \cdot \mathrm{mL}^{-1}$ tissue which is normalized to injected dose and body weight. Mean values of $\left[{ }^{123} \mathrm{I}\right]-M I B G$ uptake are calculated in each myocardial region of interest. ${ }^{25}$ The images can be normalized to the highest pixel value in the $\mathrm{LV}$ and expressed as a percentage of this value. Uptake of [ $\left.{ }^{123} \mathrm{I}\right]-\mathrm{MIBG}$ may also be presented as heart/mediastinal ratio and the clearance rate from the myocardium calculated as the initial myocardial [ $\left.{ }^{123} \mathrm{I}\right]-\mathrm{MIBG}$ uptakedelayed myocardial [ $\left.{ }^{123} \mathrm{I}\right]-\mathrm{MIBG}$ uptake/initial myocardial $\left[{ }^{123} \mathrm{I}\right]-\mathrm{MIBG}$ uptake $\times 100$. A semiquantitative analysis involves scoring images by blinded observers using a scoring system for each segment, which typically ranges from absence of detectable tracer to normal tracer retention and a "defect score" obtained.

HED. More recently, the radiotracer $\left[{ }^{11} \mathrm{C}\right]-\mathrm{HED}$ ([a $\mathrm{N}-\left[{ }^{11} \mathrm{C}\right]$ methyl-metaraminol) has been de- veloped as a NE analogue for PET. ${ }^{21,27,40}$ This tracer shares many of the kinetic properties described above for MIBG in that it undergoes highly specific and rapid uptake into the neuron by energy-dependent uptake- 1 and is nonmetabolized. ${ }^{28}$ Retention of $\left[{ }^{11} \mathrm{C}\right]-\mathrm{HED}$ in the heart is dependent upon continuous recycling into and out of the neuron ${ }^{27,28}$ and neuronal retention requires intact vesicular storage. Nonneuronal $\left[{ }^{11} \mathrm{C}\right]-\mathrm{HED}$ retention is low, and its extraction from blood to the neuronal axoplasm very high ${ }^{28}$ suggesting that its retention in the myocardium reflects the presence of intact neuronal terminals. Compared to MIBG, cross-species tracer kinetics may be more uniform. In the rat and canine heart for example, pharmacological inhibition of neuronal uptake-1 with desipramine or inhibition of vesicular storage with reserpine produces a $>90 \%$ reduction of tracer retention, 27,28 indicating the high specificity of this tracer for neuronal binding sites. $\left[{ }^{11} \mathrm{C}\right]-\mathrm{HED}$ has been extensively evaluated in diabetic patients, $17,21,24$ and in subjects whom have suffered neuronal loss secondary to ischemic heart disease. ${ }^{41}$ In the transplanted human heart, studies using $\left[{ }^{11} \mathrm{C}\right]-\mathrm{HED}$ have demonstrated increased tracer retention in the proximal anterior wall which correlated with presence of axons on histological assessment ${ }^{42}$ and with increased coronary blood flow in response to sympathetic activation, ${ }^{42}$ thus confirming the neuronal specificity of HED-PET and its ability to quantitate regional sympathetic reinnervation. However, this tracer also has important limitations, since its very rapid uptake from the interstitium to neuronal axoplasm by uptake-1 results in highly flow dependent tissue uptake and difficulty in quantitation of the uptake-1 component of tracer kinetics using compartmental modeling. ${ }^{28}$

Evaluation of myocardial retention of $\left[{ }^{11} \mathrm{C}\right]-$ HED can be performed semiquantitatively or quantitatively. Cardiac PET imaging is performed using $\sim 20 \mathrm{mCi}\left[{ }^{11} \mathrm{C}\right]-\mathrm{HED}$ and $20 \mathrm{mCi}$ $\left[{ }^{13} \mathrm{~N}\right]$-ammonia over $60 \mathrm{~min} .{ }^{21,24}$ Fifteen contiguous transaxial images (oriented perpendicular to the sagittal and coronal planes of the body) with a slice thickness of $6.75 \mathrm{~mm}$ can be obtained. Following a 15-min transmission study, tracer is injected intravenously and data acquired dynamically in frame mode to deter- 
mine tracer activity in both the blood and myocardium. ${ }^{21,24}$ After waiting $1 \mathrm{~h}$ for the ${ }^{11} \mathrm{C}$ decay after the end of data acquisition, resting myocardial perfusion is evaluated using $\left[{ }^{13} \mathrm{~N}\right]-$ ammonia. Emission data are attenuation corrected and reconstructed using filtered back projection. Images are realigned perpendicular to the long axis of the LV yielding eight short axis views (slice thickness of $0.8 \mathrm{~cm}$ ) of myocardial tracer distribution extending from the apex to the base of the LV.

The homogeneity of LV $\left[{ }^{11} \mathrm{C}\right]-\mathrm{HED}$ retention is assessed by performing circumferential count-profile analysis on each of the eight short-axis images. Each short-axis slice is divided into 36 angular regions of interest ("sectors") and the myocardial concentration of $\left[{ }^{11} \mathrm{C}\right]-\mathrm{HED}$ in each sector is determined. Regional variation of myocardial retention of $\left[{ }^{11} \mathrm{C}\right]-\mathrm{HED}$ is assessed by dividing the mean PET counts in each of the sectors by the value found in the sector containing the maximum mean PET counts. These normalized $\left[{ }^{11} \mathrm{C}\right]-\mathrm{HED}$ retention data are displayed as polar coordinate maps of relative tracer activity. The map can divided into nine regions as shown schematically in Figure 1. In this map, the LV myocardium is depicted with the apex at the center, the distal LV segments (anterior, septal,

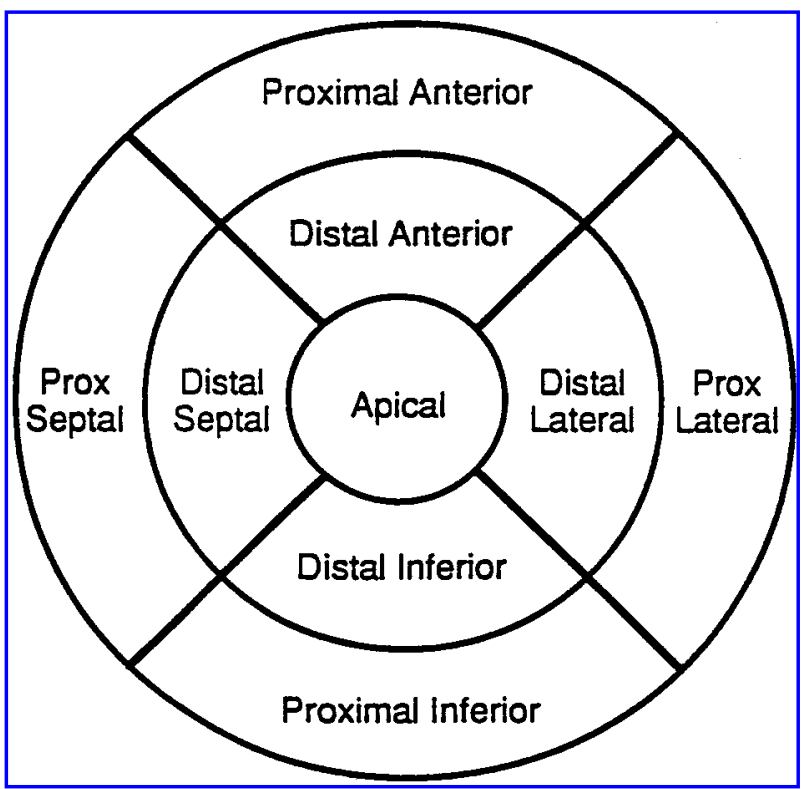

FIG. 1. Representation of the left ventricle as a polar map. Individual profiles are generated for each image and the map divided into nine regions of relative tracer activity. inferior, and lateral) as the inner ring, and the corresponding proximal segments as the outer ring. The heterogeneity of regional $\mathrm{LV}\left[{ }^{11} \mathrm{C}\right]-$ HED retention in each diabetic patient is compared to the normal reference distribution by calculating a $z$-score, $z_{i}=\left(q_{i}-\mu_{i}\right) / \sigma_{i}$, where $q_{i}$ is the relative $\left[{ }^{11} \mathrm{C}\right]-\mathrm{HED}$ retention value in the $i$ th sector value of the diabetic polar map, and $\mu_{i}$ and $\sigma_{i}$ are the mean and standard deviations of the relative $\left[{ }^{11} \mathrm{C}\right]-\mathrm{HED}$ retention in the $i$ th sector of the reference polar map. In the diabetic subjects, sectors that had a $z$-score greater than 2.5 can be defined as abnormal. Thus, the calculated $z$-scores represent a validated 21,24 measure of the individual subject's myocardial tracer retention heterogeneity, with an increase of heterogeneity being consistent with distal left ventricular denervation. ${ }^{21,24}$ The "extent" of the heterogeneity can be expressed as the percentage of sectors in the polar map that are abnormal, i.e., $z_{i}>2.5$.

In order to quantify changes in regional myocardial uptake of $\left[{ }^{11} \mathrm{C}\right]-\mathrm{HED}$, absolute $\left[{ }^{11} \mathrm{C}\right]-\mathrm{HED}$ retention in the proximal and distal LV myocardium can be measured using a "retention index" approach, ${ }^{19}$ which corrects $\left[{ }^{11} \mathrm{C}\right]-\mathrm{HED}$ retention for myocardial tracer delivery. Absolute tissue retention of $\left[{ }^{11} \mathrm{C}\right]-\mathrm{HED}$ at $40-60 \mathrm{~min}$ after injection is measured by determining mean tracer counts/pixel within the myocardial regions and corrected for tracer delivery. A $\left[{ }^{11} \mathrm{C}\right]-$ HED retention index is calculated as follows:

Retention index $(\mathrm{mL}$ blood $/ \mathrm{min} / \mathrm{mL}$ tissue $)=$ Tissue counts between 40-60 $\mathrm{min}$

$\int$ Blood counts at time $0-60 \mathrm{~min}$

\section{RESULTS}

Scintigraphic techniques have been extensively utilized to characterize sympathetic nerve fiber integrity in a wide range of different disease states including diabetes. In crosssectional studies, deficits of LV [ $\left.{ }^{123} \mathrm{I}\right]-\mathrm{MIBG}$ and $\left.{ }^{[11} \mathrm{C}\right]-\mathrm{HED}$ retention have been identified in type $1^{17,19,21-25,28,43}$ and type $2^{44-48}$ diabetic subjects with $17,18,20,21,24$ and without ${ }^{18,21,22,24,49} \mathrm{ab}$ normalities on cardiovascular reflex testing. Widespread abnormalities of myocardial LV 
$\left[{ }^{123} \mathrm{I}\right]-\mathrm{MIBG}$ have been uptake reported in metabolically compromised newly diagnosed type 1 diabetic subjects which are partially correctable by intensive insulin therapy ${ }^{23,26,50}$ and appear to be indicative of an hyperglycemia or insulin deficiency-induced acute neuronal dysfunction. Deficits of cardiac $\left[{ }^{11} \mathrm{C}\right]-\mathrm{HED}$ retention have been detected in $40 \%$ of diabetic subjects without CAN on reflex testing. ${ }^{24}$ These deficits typically begin in the distal inferior wall of the LV and with more severe neuropathy, extend to involve the distal and proximal anterolateral and inferior walls (Fig. 2). Comparison of the extent of abnormalities of $\left[{ }^{11} \mathrm{C}\right]-$ HED retention with reflex measures of sympathetic CAN revealed that an abnormal Valsalva ratio or a systolic blood pressure fall in excess of $20 \mathrm{~mm} \mathrm{Hg}$, roughly corresponds with at least $40 \%$ of the left ventricle being denervated. ${ }^{24}$

A beneficial effect of metabolic control on the development or progression of CAN should significantly improve the overall prognosis for diabetes. The relationship of metabolic control to progression of abnormalities of autonomic function has been unclear. Improved metabolic control as been reported to slow the progression of HRV deficits in type 1 diabetic patients in some studies ${ }^{51-54}$ but not in others. ${ }^{55}$ This variability could reflect a number of factors including inadequacy of glycemic control, insufficient study duration, too advanced CAN or the insensitivity of the cardiovascular autonomic function tests utilized. A recent scintigraphic study using MIBG-SPECT demonstrated that poor glycemic control resulted in the progression of LV sympathetic dysinnervation, which can be prevented ${ }^{25}$ by the institution of near-euglycemia. We also performed a 3-year prospective, observational study evaluating the effects of diabetes control on small deficits of LV sympathetic innervation in type 1 diabetic subjects. ${ }^{56}$ All the subjects had small deficits of cardiac sympathetic innervation at baseline, affecting typically less than $10 \%$ of the left ventricle (Fig. 3). One group of subjects continued to have poor diabetes control, with an average $\mathrm{HbA1}$ c above $9 \%$ over the three years. The second group achieved tight diabetes control with a mean $\mathrm{HbA} 1 \mathrm{c}$ of just below $7 \%$. With good diabetes control, the extent of the $\left[{ }^{11} \mathrm{C}\right]-$ HED retention deficit seen became significantly smaller. In contrast, there was a threefold increase in the extent of the deficit with poor diabetes control (Fig. 3). Thus quantitative scintigraphic imaging techniques such as HED-PET and MIBG-SPECT have confirmed the importance of glycemic control in the development, progression or reversal of myocardial sympathetic dysinnervation.

In diabetes, LV sympathetic dysinnervation may contribute to enhanced cardiac risk. ${ }^{3-7,57}$ Overall, a 5-year mortality approaching 30\%,58 has been observed in diabetic patients with a spectrum of severities of CAN with the highest mortality rates observed in subjects with advanced deficits of cardiovascular sympathetic innervation. ${ }^{3}$ Diabetic patients have increased mortality postmyocardial infarction, ${ }^{57}$ which may reflect the extent of coronary artery disease or increased susceptibility to other triggering factors, ${ }^{59}$ including autonomic imbalance. Impaired retention of sympathetic neurotransmitter analogues consistent with neuronal dysfunction or loss has been reported in patients with malignant ventricular dysrhythmias both in the absence ${ }^{59,60}$ or presence ${ }^{35}$ of ischemic heart disease. Decreased [ $\left.{ }^{123} \mathrm{I}\right]-\mathrm{MIBG}$ retention has been found in subjects with silent ${ }^{20,61,62}$ or symptomatic ${ }^{62}$ myocardial ischemia. These lesions are usually situated in the inferior and posterior LV segments. ${ }^{19,22,44,45}$ Abnormal myocardial $\left[{ }^{123} \mathrm{I}\right]-\mathrm{MIBG}$ uptake has been reported in subjects with altered LV diastolic filling, ${ }^{19,63}$ and correlated with myocardial electrophysiological abnormalities involving the QT interval $^{64}$ and QT dispersion. ${ }^{46}$ Impaired retention of LV [ $\left.{ }^{123} \mathrm{I}\right]-\mathrm{MIBG}$ in diabetic subjects is also predictive of sudden death. ${ }^{65}$

Quantitative regional analysis of LV sympathetic innervation using HED-PET has revealed a pattern of dysinnervation, which may predispose to myocardial electrical instability. Absolute $\left[{ }^{11} \mathrm{C}\right]-\mathrm{HED}$ retention has been reported to be increased by $\sim 30 \%$ in the proximal segments of the severe CAN subjects when compared to the same regions in mild CAN or CAN-free subjects ${ }^{24}$ (Fig. 4). Despite the increase of tracer retention, no appreciable washout of tracer is observed in the proximal segments, consistent with normal regional tone but increased sympathetic innervation. Distally, $\left[{ }^{11} \mathrm{C}\right]-\mathrm{HED}$ retention is decreased in se- 
A

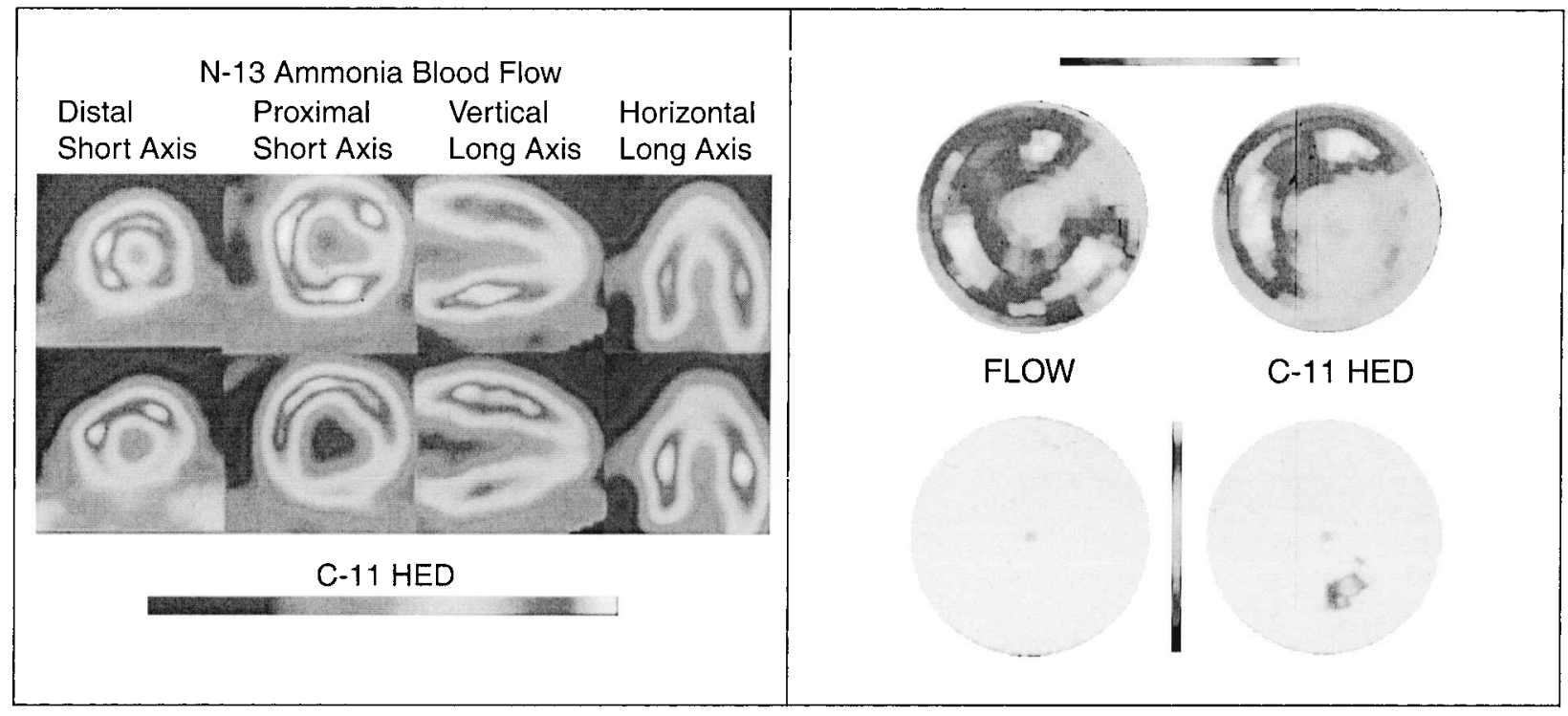

B

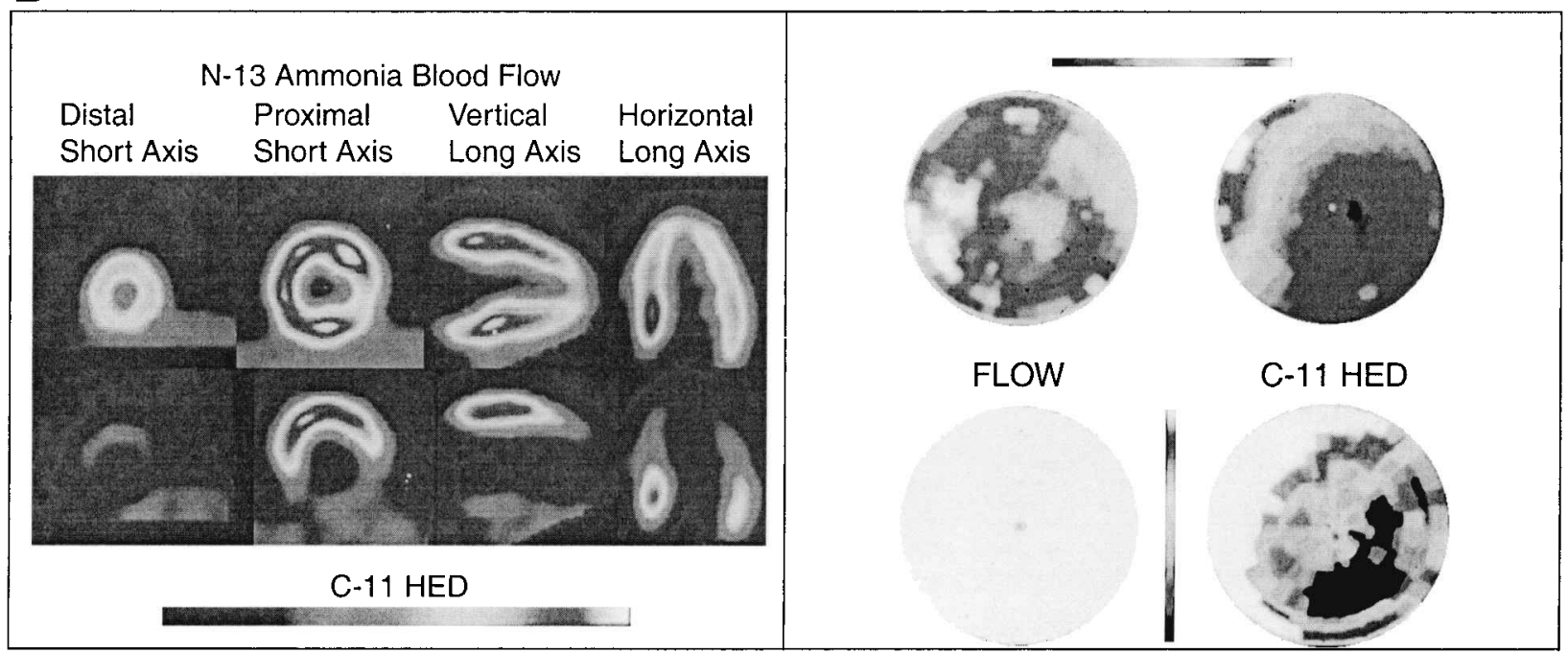

FIG. 2. Time-dependent changes in PET images of the LV from a 26-year-old female CAN subject. These two sets of images demonstrate the change in LV sympathetic innervation associated with poor metabolic control. (A) LV short and long axis views (left) and polar map images (right) at baseline. (B) The corresponding images after 5 years. In A, despite the apparent normality of both the LV blood flow images and $\left[{ }^{11} \mathrm{C}\right]-\mathrm{HED}$ distribution, a small deficit of $\left[{ }^{11} \mathrm{C}\right]-$ HED retention $(5 \%)$ is detectable on the polar map (right panel). With progression of CAN (B), abnormalities of [11C]HED retention are now extensive on all images, with only the proximal cardiac segments being preserved. DSA, distal short axis; PSA, proximal short axis; HLA, horizontal long axis; VLA, vertical long axis.

vere CAN by $\sim 30 \%$ when compared to the CAN-free diabetic subjects. ${ }^{24}$ Therefore, a considerable gradient of cardiac sympathetic innervation occurs in the LV of CAN subjects, a pattern likely to be electrically unstable. Moreover, in CAN subjects on adenosine stress, global coronary flow reserve (CFR) was decreased by over $50 \%$ compared to the CAN-free diabetic and nondiabetic control subjects, with the maximal impairment of CFR being observed in the innervated proximal myocardial segments. ${ }^{17}$ Cold pressor testing (application of 


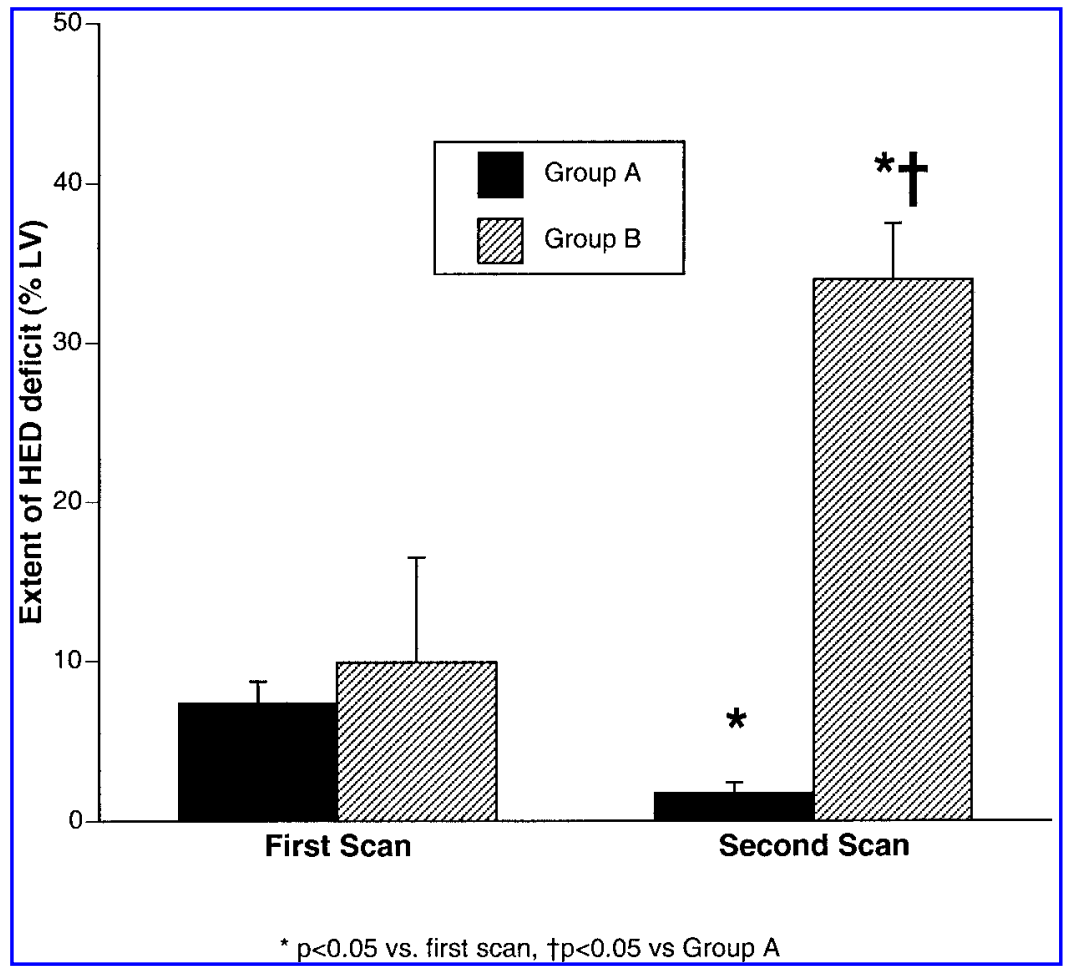

FIG. 3. Extent of $\left[{ }^{11} \mathrm{C}\right]-\mathrm{HED}$ retention abnormalities detected at baseline and after 3 years in diabetic subjects with good glycemic control (group A), compared to poor glycemic control (group B). Data shown as mean \pm 1 SEM. ${ }^{*} p<$ 0.05 vs. baseline study; $+p<0.01$ vs. group A. (Reproduced with permission from Stevens et al. ${ }^{56}$ )

an ice pack to produce sympathetic activation) has also been used to explore endothelium-dependent myocardial blood flow regulation in diabetic subjects with and without CAN. On sympathetic activation, global myocardial perfusion increased significantly in the CAN-free diabetic subjects but decreased in the CAN subjects. ${ }^{66}$ In CAN subjects, the paradoxical reduction in myocardial blood flow appeared restricted to the proximal innervated myocardial segments (Fig. 5). These data suggest that myocardial neurovascular regulation is perturbed in CAN subjects and may contribute to enhanced cardiac risk.

\section{DISCUSSION}

CAN is a common complication of diabetes associated with significant morbidity and mortality. ${ }^{3-7}$ Standardized reflex tests of autonomic function have demonstrated that deficits of sympathetic CAN are most predictive of increased mortality, ${ }^{3}$ but the mechanisms of this enhanced risk are poorly understood. The development of scintigraphic imaging techniques has allowed direct visualization and quantitation of cardiac sympathetic integrity. Studies using radiolabeled analogues of NE have shown that regional LV sympathetic dysinnervation is a common complication of disease states such as diabetes and can rapidly progress with poor metabolic control. ${ }^{25,56}$ Deficits of regional myocardial innervation are associated with altered myocardial blood flow regulation, ${ }^{17,66,67}$ which may contribute to regional electrical and chemical instability and malignant arrhythmogenesis. Future studies using scintigraphy will be aimed at characterizing the metabolic and functional consequences of regional LV denervation complicating diabetes, with the overall aim of reducing cardiac risk.

Radiolabeled analogues of NE which are actively taken up by the sympathetic nerve terminals of the heart permit direct and highly sensitive assessment of cardiac sympathetic integrity. Cardiac scanning with [ $\left.{ }^{123} \mathrm{I}\right]-\mathrm{MIBG}$ for example, has identified sympathetic denerva- 


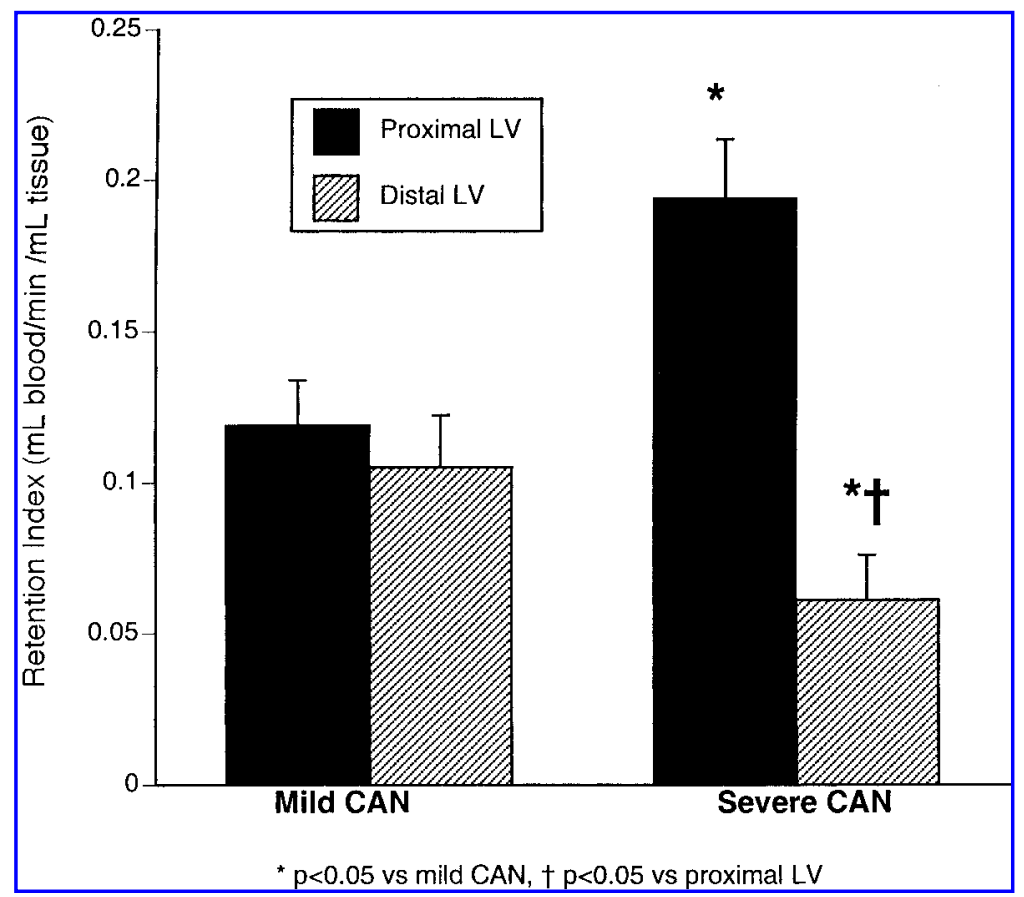

FIG. 4. Comparison of absolute $\left[{ }^{11} \mathrm{C}\right]-\mathrm{HED}$ retention in the proximal compared to distal myocardial segments in diabetic subjects with mild and severe CAN. ${ }^{*} p<0.05$ vs. other groups; $+p<0.05$ vs. proximal segments. (Reproduced from Stevens et al. $^{24}$ )

tion in the majority of diabetic subjects with normal cardiovascular reflex testing, ${ }^{18,22,48}$ with abnormalities of MIBG retention correlating with LV dysfunction. ${ }^{19,63}$ Studies using $\left[{ }^{11} \mathrm{C}\right]-\mathrm{HED}$ have confirmed that small $(<10 \%)$ deficits of LV [ $\left.{ }^{11} \mathrm{C}\right]-H E D$ retention can be observed in diabetic subjects without CAN on reflex testing, ${ }^{24,56}$ but the percentage of subjects affected is less $(\sim 40 \%)$ than is observed using MIBG. These small, metabolically correctable deficits, are observed selectively in the distal inferolateral wall of the LV. ${ }^{26,56}$ These could reflect different types of neuronal dysfunction including impaired neurotransmitter uptake, defective vesicular storage and/or complete neuronal loss. As CAN advances, the retention of $\left[{ }^{11} \mathrm{C}\right]-\mathrm{HED}$ in the LV is remarkably heterogeneous since as the extent of the distal deficits increase, ${ }^{24}$ tracer retention becomes paradoxically increased in the proximal myocardial segments consistent with proximal hyperinnervation. The etiology of increased tracer retention in these proximal segments is unknown. Potentially, increased tracer retention could result from mechanisms including; increased axonal regeneration and sprouting (as has been ob- served in the diabetic peripheral somatic nerve $)^{68}$; reduced sympathetic tone leading to decreased NE release (although little neuronal $\left[{ }^{11} \mathrm{C}\right]-\mathrm{HED}$ wash out is observed during the time frame of the imaging periods utilized ${ }^{24,28}$ or increased tracer delivery (differences in resting regional perfusion have not been detected in CAN subjects). Detailed tracer kinetic studies together with histological examination of the myocardium is required to address these possibilities.

Scintigraphic techniques have shed new light on the relationships of metabolic control to deficits of cardiac sympathetic innervation. ${ }^{25,26,56}$ The reversal of widespread abnormalities of myocardial MIBG uptake reported in newly diagnosed type 1 subjects, and the reduction of small deficits of LV $\left[{ }^{11} \mathrm{C}\right]-\mathrm{HED}$ retention with intensive insulin therapy ${ }^{26,50,56}$ parallel the improvement of the low and high frequency components of spectral analysis in subjects with early CAN. ${ }^{69}$ These data are consistent with a reversible hyperglycemia or insulin deficiency-induced acute neuronal dysfunction rather than neuronal loss. With continued poor metabolic control, deficits in 


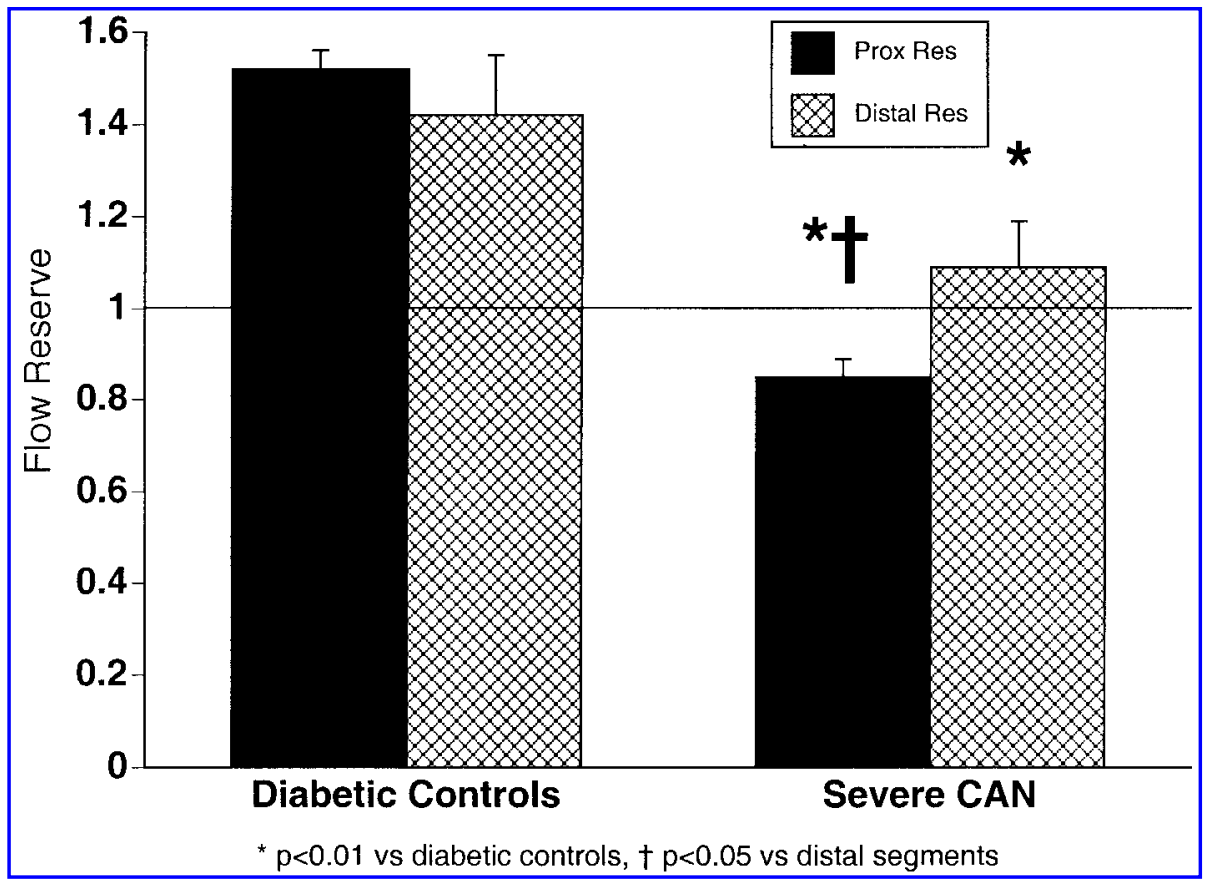

FIG. 5. Effect of sympathetic activation (a cold pressor test) on regional myocardial blood flow in the proximal vs. distal LV segments of healthy diabetic controls and diabetic subjects with severe CAN.

the retention of both $\left[{ }^{123} \mathrm{I}\right]-\mathrm{MIBG}$ and $\left[{ }^{11} \mathrm{C}\right]-$ HED can rapidly progress, ${ }^{25,56}$ and likely reflect structural neuronal damage. Additional studies are required to determine whether improved metabolic control alone, or in concert with therapeutic interventions can reverse these more extensive deficits. Reinnervation of the myocardium is a therapeutic possibility. Both HED-PET ${ }^{42,67}$ and MIBG-SPECT ${ }^{70}$ have demonstrated increased tracer retention in proximal myocardial segments of cardiac transplant patients which correlated with presence of axons on histological assessment, ${ }^{42}$ increased coronary blood flow in response to sympathetic activation, ${ }^{42}$ and the release of myocardial NE. ${ }^{42}$ Scintigraphic evaluation of cardiac reinnervation may therefore be considered a sensitive noninvasive surrogate for nerve biopsy that has been considered a "gold standard" (although invasive) end point in therapeutic clinical trials of patients with peripheral somatic neuropathy. ${ }^{68}$

Although clinical studies in diabetic patients have extensively utilized either MIBG-SPECT or HED-PET, other $\left[{ }^{11} \mathrm{C}\right]$-labeled tracers with different kinetic properties are currently being evaluated. Like $\left[{ }^{11} \mathrm{C}\right]-\mathrm{HED}$, the sympath- omimetic amines $\left[{ }^{11} \mathrm{C}\right]$-phenylephrine (PHEN) and $\left[{ }^{11} \mathrm{C}\right]$-epinephrine (EPI) are all taken up into the sympathetic neurons by the uptake-1 transporter, but are retained by different mechanisms. ${ }^{28} \mathrm{PHEN}^{71}$ and $\mathrm{EPI}^{72}$ are highly neuronal selective, but unlike HED, are subject to degradation by MAO. EPI, although initially taken up into the neuron by uptake-1, is largely retained in the neuron by highly efficient vesicular storage, with very little washout. ${ }^{28}$ The retention of EPI in rat heart is greatly decreased by pretreatment with reserpine (which inhibits vesicular uptake) ${ }^{72}$ is not chased by desipramine (which inhibits uptake-1 transport), confirming the intraneuronal localization of EPI. ${ }^{28}$ This tracer may be particularly well suited to the study of vesicular integrity. PHEN is also rapidly taken up into the storage vesicles, but is less efficiently retained, since desipramine only marginally increases the washout rate from the rat heart. ${ }^{28}$ Since its washout from the nerve terminal is greatly increased by reserpine, and its retention enhanced by the MAO-A inhibitor clorgyline, ${ }^{28,71}$ this tracer may be well suited to the study of MAO activity. Thus the different kinetic properties of these tracers, affords a unique oppor- 


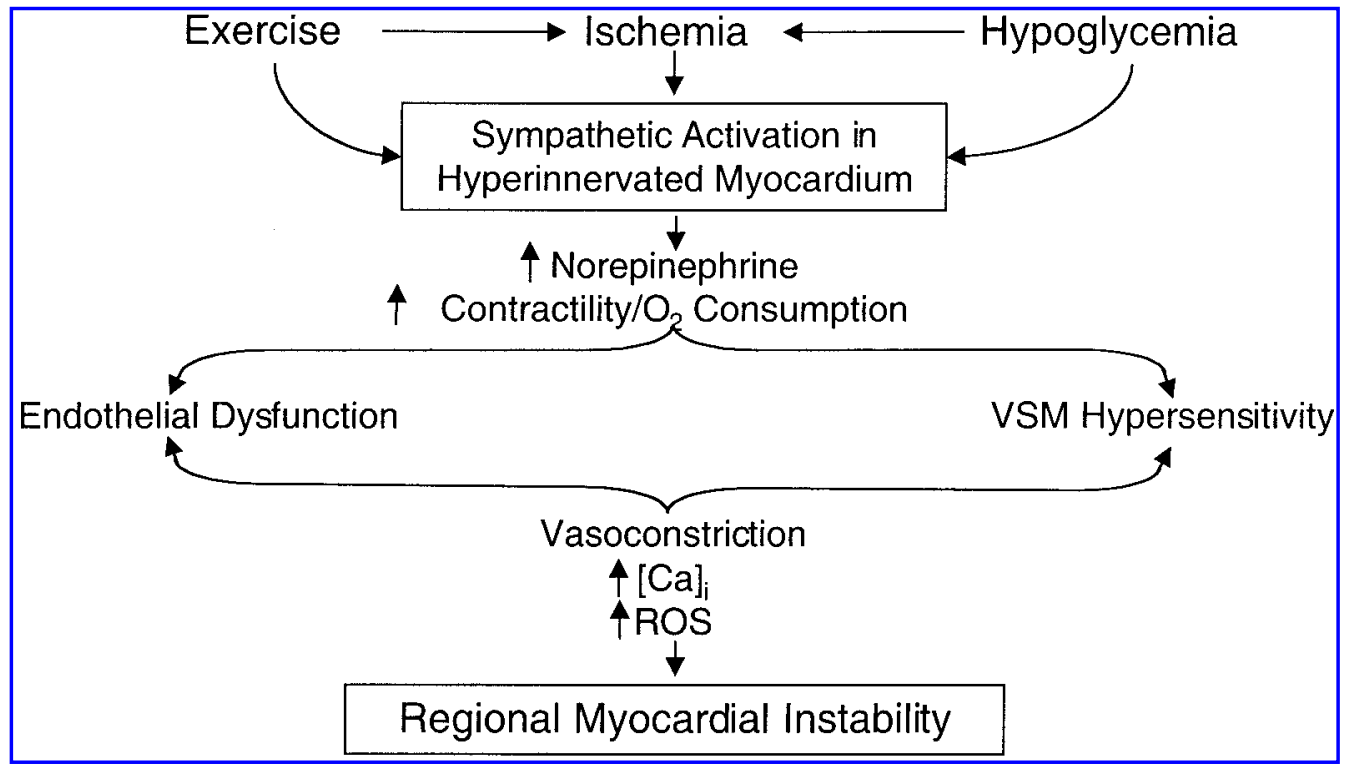

FIG. 6. Hypothetical scheme delineating the potential links between regional hyperinnervation and myocardial instability complicating diabetes. VSM, vascular smooth muscle; ROS, reactive oxygen species.

tunity to evaluate different components of neuronal function: uptake-1 (HED), vesicular integrity (EPI), or MAO activity (PHEN). Their use in diabetic patients should yield important information about the effects of glucose on neuronal function.

Recently scintigraphic techniques have been utilized in humans to better understand the relationships between myocardial innervation and blood flow regulation in diabetes. $17,66,67,73$ The integrity of myocardial sympathetic innervation has been determined by HED-PET and correlated with regional myocardial vascular responsiveness using $\left[{ }^{13} \mathrm{~N}\right]-\mathrm{NH} 3-\mathrm{PET}$ at rest and after endothelium-dependent or endothelium-independent vasodilation in diabetic subjects with and without CAN. ${ }^{17,66,67,73}$ Diabetic subjects with CAN have been found to have elevated resting myocardial perfusion, ${ }^{17}$ which is consistent with the resting tachycardia, and resultant increased myocardial oxygen requirements. No regional differences in resting perfusion were identified however, irrespective of the integrity of sympathetic innervation, which is consistent with studies in the experimentally denervated animal heart. ${ }^{74,75}$ After maximal vasodilation with adenosine, global CFR is decreased only in subjects with advanced CAN (who also frequently exhibited diabetic retinopathy and/or nephropathy ${ }^{17}$ ), consistent per- haps, with the presence of myocardial diabetic microangiopathy ${ }^{76,77}$ (coronary artery disease was excluded in these subjects ${ }^{17}$ ). Unlike the studies at rest, exploration of myocardial innervation/blood flow relationships in response to stress, have begun to yield some interesting correlations. In response to adenosine, for example, maximal impairment of vasodilatory capacity in CAN subjects is observed in the myocardial regions with persistent innervation. ${ }^{17} \mathrm{On}$ cold pressor testing, myocardial endotheliumdependent vasodilation is maximally impaired in subjects with sympathetic CAN, ${ }^{66,73}$ and myocardial perfusion may actually decrease in the regions of persistent sympathetic innervation $^{66}$ (Fig. 5). Therefore these studies have revealed complex interrelationships between diabetes, myocardial innervation and blood flow regulation.

Altered patterns of myocardial blood flow regulation are beginning to emerge which may shed light on the mechanisms of enhanced cardiac risk complicating diabetes. The role of CAN in the development of enhanced cardiac risk complicating diabetes however remains controversial and as yet unproven. As discussed above, direct scintigraphic characterization of CAN has offered a unique opportunity to address this issue. Although CAN has been invoked in sudden cardiac death even in 
diabetic subjects without myocardial ischemia, ${ }^{4,5} \mathrm{CAN}$ is frequently found in association with many established cardiovascular risk factors, ${ }^{78}$ which makes problematic the attribution of the component directly attributable to CAN. A number of observations have suggested a role for $\mathrm{CAN}$ in advanced cardiac risk. In addition to observational longitudinal studies in which the highest mortality is observed in diabetic patients with symptomatic, sympathetic $\mathrm{CAN}^{3}{ }^{3}$ a number of other observations have suggested a causal relationship. For example, decreased HRV has been shown to be an independent risk factor for mortality in subjects after myocardial infarction. ${ }^{79,80}$ In CAN, delayed cardiac repolarization and increased variability of ventricular refractoriness is associated with impaired sympathetic integrity and is correlated with QT interval lengthening. ${ }^{64}$ An association between parasympathetic CAN and LV diastolic dysfunction has recently been reported in type 1 diabetic subjects. ${ }^{81}$ Our studies using HED-PET have led us to propose a potential mechanism for enhanced cardiac risk complicating CAN. Sympathetic activation in the hyperinnervated myocardium may result in regional accumulation of NE. This will facilitate enhanced contractility and oxygen consumption, which in the presence of endothelial dysfunction and vascular smooth muscle hypersensitivity may precipitate regional vasoconstriction, increased intracellular calcium levels, and increased oxidative stress, resulting in regional myocardial instability (Fig. 6). Conversely, the denervated myocardium may also be metabolically unstable. Denervation has been shown to down-regulate glucose transport, ${ }^{82}$ and may further increase the dependence of the diabetic myocardium on free fatty acid utilization. Increased free fatty acid metabolism further impairs glucose oxidation and promotes myocardial energy deficits leading to apoptosis. ${ }^{83,84}$ Thus both the persistence of aberrant regional hyperinnervation as well as loss of sympathetic integrity could contribute to myocardial electrical instability complicating diabetes.

The recent emergence of scintigraphic techniques has revealed new insights into the effects of diabetes on myocardial innervation and blood flow regulation. Future studies with dif- ferent tracers will allow further characterization of neuronal dysfunction complicating diabetes and improve understanding of the effects of diabetes on myocardial substrate metabolism. Interventional therapeutic studies will shortly be undertaken using HED-PET in order to assess the reversibility of sympathetic dysinnervation in diabetic subjects with advanced CAN.

\section{ACKNOWLEDGMENTS}

M.J.S. is supported by USPHS Research Grant R01-DK52391 and a Veterans Administration Career Development Award.

\section{REFERENCES}

1. Stevens MJ, Edmonds ME, Mathias CJ, Watkins PJ: Disabling postural hypotension complicating diabetic autonomic neuropathy. Diabet Med 1991;8:870-874.

2. Edmonds ME, Archer AG, Watkins PJ: Ephedrine: a new treatment for diabetic neuropathic oedema. Lancet 1983;1:548-551.

3. Ewing DJ, Campbell IW, Clarke BF: The natural history of diabetic autonomic neuropathy. Q J Med 1980; 49:95-108.

4. O'Brien OA, McFadden JP, Corrall RJM: The influence of autonomic neuropathy on mortality in insulindependent diabetes. Q J Med 1991;290:295-502.

5. Rathman W, Ziegler D, Jahnke M, Haastert B, Gries FA: Mortality in diabetic patients with cardiovascular autonomic neuropathy. Diabet Med 1993;10:820824.

6. Page MM, Watkins PJ: The heart in diabetes: autonomic neuropathy and cardiomyopathy. Clin Endocrinol Metab 1977;6:377-388.

7. Zola B, Kahn JK, Juni JE, Vinik AI: Abnormal cardiac function in diabetic patients with autonomic neuropathy in the absence of ischemic heart disease. J Clin Endocrinol Metab 1986;63:208-214.

8. Ewing DJ, Martyn CN, Young RJ, Clarke BF: The value of cardiovascular autonomic function tests: 10 years experience in diabetes. Diabetes Care 1985;8: 491-498.

9. Hilsted J, Jensen SB: A simple test for autonomic neuropathy in juvenile diabetics. Acta Med Scand 1979; 205:385-387.

10. Dyrberg T, Benn J, Christiansen JS, Hilsted J, Nerup $\mathrm{J}$ : Prevalence of diabetic autonomic neuropathy measured by simple bedside tests. Diabetologia 1981;20: 190-194.

11. Kennedy WR, Navarro X, Sakuta M, Mandell H, Knox CK, Sutherland DE: Physiological and clinical correlates of cardiorespiratory reflexes in diabetes mellitus. Diabetes Care 1989;12:399-408. 
12. Neil HA, Thompson AV, John S, McCarthy ST, Mann JI: Diabetic autonomic neuropathy: the prevalence of impaired heart rate variability in a geographically defined population. Diabet Med 1989;6:20-24.

13. Microvascular and acute complications in IDDM patients: the EURODIAB IDDM Complications Study. Diabetologia 1994;37:278-285.

14. Ziegler D, Dannehl K, Muhlen H, Spuler M, Gries FA: Prevalence of cardiovascular autonomic dysfunction assessed by spectral analysis, vector analysis, and standard tests of heart rate variation and blood pressure responses at various stages of diabetic neuropathy. Diabet Med 1992;9:806-814.

15. Canal N, Comi G, Saibene V, Musch B, Pozza G: The relationship between peripheral and autonomic neuropathy in insulin-dependent diabetes: a clinical and instrumental evaluation. In: Cana N, Pozza, G, eds. Peripheral Neuropathies. Amsterdam: Elsevier North-Holland, 1978:247-255.

16. Ewing DJ, Campbell IW, Clarke BF: Assessment of cardiovascular effects in diabetic autonomic neuropathy and prognostic implications. Ann Intern Med 1980;92:308-311.

17. Stevens MJ, Dayanikli F, Raffel DM, Allman KC, Sandford T, Feldman EL, Wieland DM, Corbett J, Schwaiger M: Scintigraphic assessment of regionalized defects in myocardial sympathetic innervation and blood flow regulation in diabetic patients with autonomic neuropathy. I Am Coll Cardiol 1998;31: 1575-1584.

18. Mantysaari M, Kuikka J, Mustonen J, Tahvanainen K, Vanninen E, Lansimies E, Uusitupa M: Noninvasive detection of cardiac sympathetic nervous dysfunction in diabetic patients using [123I]metaiodobenzylguanidine. Diabetes 1992;41:1069-1075.

19. Kreiner G, Wolzt M, Fasching P, Leitha T, Edlmayer A, Korn A, Waldhausl W, Dudczak R: Myocardial $\left.\mathrm{m}-{ }^{123} \mathrm{I}\right]$ iodobenzylguanidine scintigraphy for the assessment of adrenergic cardiac innervation in patients with IDDM. Comparison with cardiovascular reflex tests and relationship to left ventricular function. Diabetes 1995;44:543-549.

20. Langer A, Freeman MR, Josse RG, Armstrong PW: Metaiodobenzylguanidine imaging in diabetes mellitus: assessment of cardiac sympathetic denervation and its relation to autonomic dysfunction and silent myocardial ischemia. J Am Coll Cardiol 1995;25:610618.

21. Allman KC, Stevens MJ, Wieland DM, Hutchins GD, Wolfe ER, Greene DA, Schwaiger M: Noninvasive assessment of cardiac diabetic neuropathy by C-11 hydroxyephedrine and positron emission tomography. J Am Coll Cardiol 1993;22:1425-1432.

22. Schnell O, Kirsch CM, Stemplinger J, Haslbeck M, Standl E: Scintigraphic evidence for cardiac sympathetic dysinnervation in long-term IDDM patients with and without ECG-based autonomic neuropathy. Diabetologia 1995;38:1345-1352.

23. Schnell O, Muhr D, Weiss M, Dresel S, Haslbeck M, Standl E: Reduced myocardial ${ }^{123}$ I-metaiodobenzyl- guanidine uptake in newly diagnosed IDDM patients. Diabetes 1996;45:801-805.

24. Stevens MJ, Raffel DM, Allman KC, Dayanikli F, Ficaro E, Sandford T, Wieland DM, Pfeifer MA, Schwaiger M: Cardiac sympathetic dysinnervation in diabetes: implications for enhanced cardiovascular risk. Circulation 1998;98:961-968.

25. Ziegler D, Weise F, Langen KJ, Piolot R, Boy C, Hubinger A, Muller-Gartner HW, Gries FA: Effect of glycaemic control on myocardial sympathetic innervation assessed by $\left[{ }^{123} \mathrm{I}\right]$ metaiodobenzylguanidine scintigraphy: a 4-year prospective study in IDDM patients. Diabetologia 1998;41:443-451.

26. Schnell O, Muhr D, Dresel S, Weiss M, Haslbeck M, Standl E: Partial restoration of scintigraphically assessed cardiac sympathetic denervation in newly diagnosed patients with insulin-dependent (type 1) diabetes mellitus at one-year follow-up. Diabet Med 1997;14:57-62.

27. DeGrado TR, Hutchins GD, Toorongian SA, Wieland DM, Schwaiger M: Myocardial kinetics of carbon-11meta-hydroxyephedrine: retention mechanisms and effects of norepinephrine. I Nucl Med 1993;34:12871293.

28. Raffel DM, Corbett JR, Schwaiger M, Wieland DM: Mechanism-based strategies for mapping heart sympathetic nerve function. Nucl Med Biol 1995;22:10191026.

29. Wieland DM, Brown LE, Tobes MC, Rogers WL, Marsh DD, Mangner TJ, Swanson DP, Beierwaltes $\mathrm{WH}$ : Imaging the primate adrenal medulla with $\left[{ }^{123} \mathrm{I}\right]$ and $\left[{ }^{131} \mathrm{I}\right]$ metaiodobenzylguanidine: concise communication. I Nucl Med 1981;22:358-364.

30. Sisson JC, Wieland DM, Sherman P, Mangner TJ, Tobes MC, Jacques S Jr: Metaiodobenzylguanidine as an index of the adrenergic nervous system integrity and function. J Nucl Med 1987;28:1620-1624.

31. Glowniak JV: Cardiac studies with metaiodobenzylguanidine: a critique of methods and interpretation of results. J Nucl Med 1995;36:2133-2137.

32. Dae MW, $\mathrm{O}^{\prime}$ Connell JW, Botvinick EH, Ahearn T, Yee E, Huberty JP, Mori H, Chin MC, Hattner RS, Herre JM, et al: Scintigraphic assessment of regional cardiac adrenergic innervation. Circulation 1989;79:634-644.

33. Sisson JC, Lynch JJ, Johnson J, Jaques S Jr, Wu D, Bolgos G, Lucchesi BR, Wieland DM: Scintigraphic detection of regional disruption of adrenergic neurons in the heart. Am Heart J 1988;116:67-76.

34. Minardo JD, Tuli MM, Mock BH, Weiner RE, Pride HP, Wellman HN, Zipes DP: Scintigraphic and electrophysiological evidence of canine myocardial sympathetic denervation and reinnervation produced by myocardial infarction or phenol application. $\underline{\text { Circula- }}$ tion 1988;78:1008-1019.

35. Stanton MS, Tuli MM, Radtke NL, Heger JJ, Miles WM, Mock BH, Burt RW, Wellman HN, Zipes DP: Regional sympathetic denervation after myocardial infarction in humans detected noninvasively using I123-metaiodobenzylguanidine. I Am Coll Cardiol 1989;14:1519-1526. 
36. Glowniak JV, Turner FE, Gray LL, Palac RT, LagunasSolar MC, Woodward WR: Iodine-123 metaiodobenzylguanidine imaging of the heart in idiopathic congestive cardiomyopathy and cardiac transplants. I Nucl Med 1989;30:1182-1191.

37. Tobes MC, Jaques S Jr, Wieland DM, Sisson JC: Effect of uptake-one inhibitors on the uptake of norepinephrine and metaiodobenzylguanidine. J Nucl Med $1985 ; 26: 897-907$.

38. Jaques S Jr, Tobes MC, Sisson JC, Baker JA, Wieland DM: Comparison of the sodium dependency of uptake of meta-iodobenzylguanidine and norepinephrine into cultured bovine adrenomedullary cells. $\underline{\mathrm{Mol}}$ Pharmacol 1984;26:539-546.

39. Nakajo M, Shimabukuro K, Yoshimura H, Yonekura R, Nakabeppu Y, Tanoue P, Shinohara S: Iodine-131 metaiodobenzylguanidine intra- and extravesicular accumulation in the rat heart. J Nucl Med 1986;27: 84-89.

40. Rosenspire KC, Haka MS, Van Dort ME, Jewett DM, Gildersleeve DL, Schwaiger M, Wieland DM: Synthesis and preliminary evaluation of carbon-11-metahydroxyephedrine: a false transmitter agent for heart neuronal imaging. J Nucl Med 1990;31:1328-1334.

41. Allman KC, Wieland DM, Muzik O, Degrado TR, Wolfe ER Jr, Schwaiger M: Carbon-11 hydroxyephedrine with positron emission tomography for serial assessment of cardiac adrenergic neuronal function after acute myocardial infarction in humans. I Am Coll Cardiol 1993;22:368-375.

42. Schwaiger M, Hutchins GD, Kalff V, Rosenspire K, Haka MS, Mallette S, Deeb GM, Abrams GD, Wieland $D$ : Evidence for regional catecholamine uptake and storage sites in the transplanted human heart by positron emission tomography. J Clin Invest 1991;87: 1681-1690.

43. Rabinovitch MA, Rose CP, Schwab AJ, Fitchett DH, Honos GN, Stewart JA, Chen LF, Castilla EP, Gomez AA, Abrahamowicz M: A method of dynamic analysis of iodine-123-metaiodobenzylguanidine scintigrams in cardiac mechanical overload hypertrophy and failure. I Nucl Med 1993;34:589-600.

44. Hattori N, Tamaki N, Hayashi T, Masuda I, Kudoh T, Tateno M, Tadamura E, Yonekura Y, Nakao K, Konishi J: Regional abnormality of iodine-123-MIBG in diabetic hearts. J Nucl Med 1996;37:1985-1990.

45. Turpeinen AK, Vanninen E, Kuikka JT, Uusitupa MI: Demonstration of regional sympathetic denervation of the heart in diabetes. Comparison between patients with NIDDM and IDDM. Diabetes Care 1996;19:10831090.

46. Shimabukuro M, Chibana T, Yoshida H, Hagamine F, Komiya I, Takasu N: Increased QT dispersion and cardiac adrenergic dysinnervation in diabetic patients with autonomic neuropathy. Am J Cardiol 1996;78: 1057-1059.

47. Murata K, Sumida Y, Murashima S, Matsumura K, Takeda H, Nakagawa T, Shima T: A novel method for the assessment of autonomic neuropathy in type 2 diabetic patients: a comparative evaluation of ${ }^{123}$ I-MIBG myocardial scintigraphy and power spectral analysis of heart rate variability. Diabet Med 1996;13:266-272.

48. Freeman MR, Newman D, Dorian P, Barr A, Langer A: Relation of direct assessment of cardiac autonomic function with metaiodobenzylguanidine imaging to heart rate variability in diabetes mellitus. Am J Cardiol 1997;80:247-250.

49. Claus D, Feistel H, Brunholzl C, Platsch G, Neundorfer B, Wolf F: Investigation of parasympathetic and sympathetic cardiac innervation in diabetic neuropathy: heart rate variation versus meta-iodo-benzylguanidine measured by single photon emission computed tomography. Clin Auton Res 1994;4:117-123.

50. Muhr-Becker D, Weiss M, Tatsch K, Wolfram G, Standl E, Schnell O: Scintigraphically assessed cardiac sympathetic dysinnervation in poorly controlled type 1 diabetes mellitus: one-year follow-up with improved metabolic control. Exp Clin Endocrinol Diabetes 1999;107:306-312.

51. Jakobsen J, Christiansen JS, Kristofferson I, Christensen C, Hermansen K, Schmitz A, Morgensen CE: Autonomic and somatosensory nerve function after 2 years of continuous subcutaneous insulin infusion in type 1 diabetes. Diabetes 1988;37:452-455.

52. DCCT: The effect of intensive treatment of diabetes on the development and progression of long-term complications in insulin-dependent diabetes mellitus. The Diabetes Control and Complications Trial Research Group. N Engl J Med 1993;329:977-986.

53. DCCT: The effect of intensive diabetes therapy on the development and progression of neuropathy. The Diabetes Control and Complications Trial Research Group. Ann Intern Med 1995;122:561-568.

54. DCCT: The effect of intensive diabetes therapy on measures of autonomic nervous system function in the Diabetes Control and Complications Trial (DCCT). Diabetologia 1998;41:416-423.

55. Lauritzen T, Frost-Larsen K, Larsen HW, Deckert T: Two-year experience with continuous subcutaneous insulin infusion in relation to retinopathy and neuropathy. Diabetes 1985;34(Suppl 3):74-79.

56. Stevens MJ, Raffel DM, Allman KC, Schwaiger M, Wieland DM: Regression and progression of cardiac sympathetic dysinnervation complicating diabetes: an assessment by C-11 hydroxyephedrine and positron emission tomography. Metabolism 1999;48: 92-101.

57. Hjalmarson A, Elmfeldt D, Herlitz J, Holmberg S, Malek I, Nyberg G, Ryden L, Swedberg K, Vedin A, Waagstein F, Waldenstrom A, Waldenstrom J, Wedel $\mathrm{H}$, Wilhelmsen L, Wilhelmsson C: Effect on mortality of metoprolol in acute myocardial infarction. A double-blind randomised trial. Lancet 1981;2:823-827.

58. Navarro X, Kennedy WR, Sutherland DER: Autonomic neuropathy and survival in diabetes mellitus: effects of pancreas transplantation. Diabetologia 1991; 34:S108-S112.

59. Mitrani RD, Klein LS, Miles WM, Hackett FK, Burt RW, Wellman HN, Zipes DP: Regional cardiac sympathetic denervation in patients with ventricular 
tachycardia in the absence of coronary artery disease. J Am Coll Cardiol 1993;22:1344-1353.

60. Calkins H, Allman K, Bolling S, Kirsch M, Wieland D, Morady F, Schwaiger M: Correlation between scintigraphic evidence of regional sympathetic neuronal dysfunction and ventricular refractoriness in the human heart. Circulation 1993;88:172-179.

61. Matsuo S, Takahashi M, Nakamura Y, Kinoshita M: Evaluation of cardiac sympathetic innervation with iodine-123-metaiodobenzylguanidine imaging in silent myocardial ischemia. J Nucl Med 1996;37:712771.

62. Koistinen MJ, Airaksinen KE, Huikuri HV, Linnaluoto MM, Heikkila J, Torniainen P, Ahonen A: No difference in cardiac innervation of diabetic patients with painful and asymptomatic coronary artery disease. Diabetes Care 1996;19:231-233.

63. Mustonen J, Mantysaari M, Kuikka J, Vanninen E, Vainio P, Lansimies E, Uusitupa M: Decreased myocardial ${ }^{123}$ I-metaiodobenzylguanidine uptake is associated with disturbed left ventricular diastolic filling in diabetes. Am Heart J 1992;123:804-805.

64. Langen KJ, Ziegler D, Weise F, Piolot R, Boy C, Hubinger A, Gries FA, Muller-Gartner HW: Evaluation of QT interval length, QT dispersion and myocardial miodobenzylguanidine uptake in insulin-dependent diabetic patients with and without autonomic neuropathy. Clin Sci (Colch) 1997;93:325-333.

65. Kahn JK, Sisson JC, Vinik AI: Prediction of sudden cardiac death in diabetic autonomic neuropathy. I Nucl Med 1988;29:1605-1606.

66. Pop-Busui R, Kirkwood I, Wieland D, Raffel D, Stevens MJ: Myocardial endothelial dysfunction complicates cardiac sympathetic dysinnervation in diabetic autonomic neuropathy. Diabetes (Suppl. 1) 1999;48:A148.

67. Di Carli MF, Tobes MC, Mangner $T$, Levine $A B$, Muzik O, Chakroborty P, Levine TB: Effects of cardiac sympathetic innervation on coronary blood flow. N Engl J Med 1997;336:1208-1215.

68. Greene DA, Arezzo J, Brown M: Dose-related effects of the aldose reductase nerve conduction velocity and nerve fiber density in human diabetic neuropathy. Diabetes 1996;45(Suppl. 2):190A.

69. Burger AJ, Weinrauch LA, D'Elia JA, Aronson D: Effect of glycemic control on heart rate variability in type I diabetic patients with cardiac autonomic neuropathy. Am J Cardiol 1999;84:687-691.

70. Estorch M, Camprecios M, Flotats A, Mari C, Berna L, Catafau AM, Ballester M, Narula J, Carrio I: Sympathetic reinnervation of cardiac allografts evaluated by ${ }^{123}$ I-MIBG imaging. J Nucl Med 1999;40:911-916.

71. Del Rosario RB, Jung YW, Caraher J, Chakrabarty PK, Wieland DM: Synthesis and preliminary evaluation of $\left[{ }^{11} \mathrm{C}\right]-(-)$ phenylephrine as a functional heart neuronal PET agent. Nucl Med Biol 1996;23:611-616.

72. Chakraborty PK, Gildersleeve DL, Jewett DM, Toorongian SA, Kilbourn MR, Schwaiger M, Wieland DM: High yield synthesis of high specific activity R$(-)-\left[{ }^{11} \mathrm{C}\right]$ epinephrine for routine PET studies in humans. Nucl Med Biol 1993;20:939-944.

73. Di Carli MF, Bianco-Batlles D, Landa ME, Kazmers A,
Groehn H, Muzik O, Grunberger G: Effects of autonomic neuropathy on coronary blood flow in patients with diabetes mellitus. Circulation 1999;100:813-819.

74. Maeda K, Fernyhough P, Tomlinson DR: Regenerating sensory neurones of diabetic rats express reduced levels of mRNA for GAP-43, gamma-preprotachykinin and the nerve growth factor receptors, trkA and p75NGFR. Brain Res Mol Brain Res 1996; 37:166-174.

75. Griggs DM Jr, Chilian WM, Boatwright RB, Shoji T, Williams DO: Evidence against significant resting alpha-adrenergic coronary vasoconstrictor tone. Fed Proc 1984;43:2873-2877.

76. Blumenthal HT, Alex M, Goldenberg S: A study of lesions of the intramural coronary artery branches in diabetes mellitus. Arch Pathol 1960;70:13-28.

77. Zoneraich S, Silverman G, Zoneraich O: Primary myocardial disease, diabetes mellitus, and small vessel disease. Am Heart J 1980;100:754-755.

78. Orchard TJ, Ce LL, Maser RE, Kuller LH: Why does diabetic autonomic neuropathy predict IDDM mortality? An analysis from the Pittsburgh Epidemiology of Diabetes Complications Study. Diabetes Res Clin Pract 1996;34(Suppl):S165-S171.

79. Van Ravenswaaij-Arts CM, Kollee LA, Hopman JC, Stoelinga GB, van Geijn HP: Heart rate variability. An Intern Med 1993;118:436-447.

80. Kleiger RE, Miller JP, Bigger JT Jr, Moss AJ: Decreased heart rate variability and its association with increased mortality after acute myocardial infarction. Am J Cardiol 1987;59:256-262.

81. Willenheimer RB, Erhardt LR, Nilsson H, Lilja B, JuulMoller S, Sundkvist G: Parasympathetic neuropathy associated with left ventricular diastolic dysfunction in patients with insulin-dependent diabetes mellitus. Scand Cardiovasc J 1998;32:17-22.

82. Block NE, Menick DR, Robinson KA, Buse MG: Effect of denervation on the expression of two glucose transporter isoforms in rat hindlimb muscle. J Clin Invest 1991;88:1546-1552.

83. Stanley WC, Lopaschuk GD, McCormack JG: Regulation of energy substrate metabolism in the diabetic heart. Cardiovasc Res 1997;34:25-33.

84. Malhotra R, Brosius FC III: Glucose uptake and glycolysis reduce hypoxia-induced apoptosis in cultured neonatal rat cardiac myocytes. J Biol Chem 1999;274: 12567-12575.

Address reprint requests to: Martin J. Stevens, M.D. Division of Endocrinology and Metabolism Department of Internal Medicine University of Michigan Medical Center Room 5570 MSRB II Box $0678 m 1150$ West Medical Center Drive Ann Arbor, MI 48109-0678

E-mail: stevensm@umich.edu 
This article has been cited by:

1. Yoji Hamada, Jiro Nakamura. 2004. Clinical Potential of Aldose Reductase Inhibitors in Diabetic Neuropathy. Treatments in Endocrinology 3:4, 245-255. [CrossRef]

2. Phillip Low. 2002. Current Opinion in Neurology 15:5, 605-609. [CrossRef] 